\title{
Liver Partial Response GvHD
}

National Cancer Institute

\section{Source}

National Cancer Institute. Liver Partial Response GVHD. NCI Thesaurus. Code C126720.

A decrease by $50 \%$ for ALT, alkaline phosphatase, and total bilirubin. 